\title{
Updated clinical guidelines experience major reporting limitations
}

Robin W.M. Vernooij ${ }^{1}$, Laura Martínez García ${ }^{1 *}$ (D), Ivan Dario Florez ${ }^{2,3}$, Laura Hildago Armas ${ }^{1}$, Michiel H.F. Poorthuis ${ }^{4}$, Melissa Brouwers ${ }^{2,5}$ and Pablo Alonso-Coello $0^{1,6}$

\begin{abstract}
Background: The Checklist for the Reporting of Updated Guidelines (CheckUp) was recently developed. However, so far, no systematic assessment of the reporting of updated clinical guidelines (CGs) exists. We aimed to examine (1) the completeness of reporting the updating process in CGs and (2) the inter-observer reliability of CheckUp.
\end{abstract}

Methods: We conducted a systematic assessment of the reporting of the updating process in a sample of updated CGs using CheckUp. We performed a systematic search to identify updated CGs published in 2015, developed by a professional society, reporting a systematic review of the evidence, and containing at least one recommendation. Three reviewers independently assessed the CGs with CheckUp (16 items). We calculated the median score per item, per domain, and overall, converting scores to a 10-point scale. Multiple linear regression analyses were used to identify differences according to country, type of organisation, scope, and health topic of updated CGs. We calculated the intraclass coefficient (ICC) and 95\% confidence interval (95\% CI) for domains and overall score.

Results: We included in total 60 updated CGs. The median domain score on a 10-point scale for presentation was 5.8 (range 1.7 to 10), for editorial independence 8.3 (range 3.3 to 10), and for methodology 5.7 (range 0 to 10). The median overall score on a 10-point scale was 6.3 (range 3.1 to 10). Presentation and justification items at recommendation level (respectively reported by 27 and 38\% of the CGs) and the methods used for the external review and implementing changes in practice were particularly poorly reported (both reported by 38\% of the CGs). CGs developed by a European or international institution obtained a statistically significant higher overall score compared to North American or Asian institutions $(p=0.014)$. Finally, the agreement among the reviewers on the overall score was excellent (ICC $0.88,95 \% \mathrm{Cl}$ 0.75 to 0.95$)$.

Conclusions: The reporting of updated CGs varies considerably with significant room for improvement. We recommend using CheckUp to assess the updating process in updated CGs and as a blueprint to inform methods and reporting strategies in updating.

Keywords: Checklist/standards, Guideline [publication type], Publishing/standards

\section{Background}

Clinical guidelines (CGs) are defined as 'statements that include recommendations intended to optimise patient care, that are informed by systematic reviews of evidence and an assessment of the benefits and harms of alternative care options' [1]. Scientific knowledge is in constant evolution $[2,3]$; therefore, surveillance of the new evidence is

\footnotetext{
*Correspondence: laura.martinez.garcia@cochrane.es

${ }^{1}$ Iberoamerican Cochrane Centre, Biomedical Research Institute Sant Pau (IIB

Sant Pau), Barcelona, Spain

Full list of author information is available at the end of the article
}

required to ensure the trustworthiness of clinical guidelines (CGs) [4-8].

Updating CGs is an iterative process with a systematic and explicit methodology that involves identifying and reviewing new evidence not included in the original version of a CG [9]. The fundamental stages of the updating process are (1) prioritising of CGs and clinical questions $[10,11],(2)$ identifying of new evidence $[8,12,13]$, (3) assessing the impact of the new evidence and decision to update $[4,8],(4)$ reviewing and-if necessary-modifying the recommendations [14-16], and (5) reporting updated recommendations [17]. Currently, there is no 
consensus about the optimal methodology to maintain CGs up-to-date [11, 18, 19].

The reporting of updated CGs is a process within an updating strategy that communicates users about the methods and changes in an updated CG [9]. So far, there is limited guidance on the reporting of the updating process [19]. To address this gap, we recently developed the Checklist for the Reporting of Updated Guidelines (CheckUp) [20]. The aim of CheckUp is to evaluate the completeness of reporting in updated CGs [20]. CheckUp can be used (1) to inform about strategies for updating CGs and their reporting requirements (CG developers), (2) to assess the reporting of updated CGs (interested CG users), and (3) to complete as a publication requirement of updated CGs (editors of scientific journals that publish CGs) [20]. Although CheckUp has been already included in some methodological handbooks and methodological studies [21, 22], it has not been yet formally implemented.

To our knowledge, updated CGs have not been systematically reviewed to assess the completeness of reporting the updating process. An overview of the current status could be informative for the CG community. Therefore, the objectives of our study were (1) to assess the completeness of reporting the updating process of updated CGs using CheckUp and (2) to explore the inter-observer reliability of CheckUp.

\section{Methods}

\section{Study design}

We conducted a systematic assessment of the reporting of the updating process in a sample of updated CGs using CheckUp. We followed the Preferred Reporting Items for Systematic Reviews and Meta-Analyses (PRISMA) guideline to the extent it was applicable to our study [23].

\section{Information sources and search strategy}

We searched in MEDLINE (accessed through PubMed), the G-I-N library (http://www.g-i-n.net), and the National Guidelines Clearinghouse (NGC) (https://www.guidelines.gov) in August 2016 for updated CGs published during 2015. The search strategy can be found in Additional file 1.

\section{Inclusion criteria}

We included all updated CGs published in 2015 (as the most recent year prior to publication of CheckUp) which met the following criteria: (1) developed by a professional society, (2) search strategy using at least one bibliographic database, (3) reporting at least one recommendation, (4) updated version of a previous version of the same CG (including a reference to a previous version of the CG), and (5) published in English.

\section{Study selection}

Two reviewers (RV, IDF, LHA, or MHFP) independently screened the titles and abstracts to identify potentially eligible references. We obtained the full-text articles of the potentially eligible references for further assessment. Disagreements were solved by consensus and, if necessary, with the help of a third reviewer (LMG).

\section{Data extraction}

CheckUp is a checklist consisting of 16 items that examine the reporting of the updating process in updated CGs [20]. CheckUp consists of three domains: (1) presentation of the updated CG (6 items), (2) editorial independence ( 3 items), and (3) the methodology of the updating process (7 items).

Three reviewers (RV, IDF, LHA, or MHFP) independently evaluated each CG with CheckUp, and whenever the included CGs referred to supplemental documents (e.g. methodological manuals or appendices), these documents were reviewed for additional information.

Furthermore, we collected the following information regarding: (1) the institution that updated the CG (name, country, and type of organisation), (2) the scope of the updated CG (diagnosis, management, prevention, screening, or treatment), and (3) the health topic of the updated CG.

\section{Data analysis}

We calculated summary statistics to provide quantitative information about the institution that updated CGs and CheckUp scores. We calculated item scores (absolute frequencies and proportions) by summing up the updated CGs that reported each item. We calculated domain scores (median and range) by summing up all scores of the individual items for each domain: presentation of the updated CG (6 items), editorial independence (3 items), and the methodology of the updating process (7 items). Additionally, we calculated the overall score (median and range) by summing up all scores of the individual items. Both domain scores and total scores were converted to a 10-point scale.

To identify potential predictors, we used multiple linear regression to test whether the overall score (dependent variable) differed between CG institution's country, type of organisation, objective of the CG, and CG topic (independent variables).

We calculated the intraclass coefficient (ICC) with its 95\% confidence interval (CI) as an indicator of the overall agreement between the three reviewers for each item. According to the scale proposed by Landis and Koch, the degree of agreement between 0.00 and 0.20 was considered poor, from 0.21 to 0.40 fair, from 0.41 to 0.60 moderate, from 0.61 to 0.80 substantial, and from 0.81 to 1.00 almost perfect [24]. 
We accepted $p$ values of less than 0.05 as significant. We performed the analyses using SPSS version 22.0 (SPSS Inc., Chicago, IL, USA).

\section{Results}

\section{Selection of updated clinical guidelines}

The screening process is summarised in a flow diagram (Fig. 1). We initially identified 1465 references and excluded 1249 references after examining their titles and abstracts. We reviewed 216 full-text articles and excluded 156 references (Additional file 2). Finally, we included 60 updated CGs [25-84].

\section{Characteristics of included clinical guidelines}

Most institutions responsible for updating the CGs were North American $(61.7 \%$; 37/60) and scientific/professional societies $(46.7 \%$; $28 / 60)$ or public institutions (43.3\%; 26/60) (Table 1). In total, 25 (41.7\%; 25/60) of the included CGs addressed the management of a specific disease. Other CGs address solely the treatment (25.0\%; 15/60), screening (15.0\%; 9/60), diagnosis $(11.7 \%$; $7 / 60)$, or prevention $(6.7 \% ; 4 / 60)$ of a healthcare problem. The clinical area of the included CGs varied widely, with oncology $(26.7 \%$; 16/60) the most common.

\section{Domain scores}

Presentation of the updated CG

All of the included updated CGs could be distinguished from their predecessors since this was one of the eligibility criteria. The included CGs often used the term 'update', 'version', or the year of publication (i.e. 2015) in their title (Table 2, Fig. 2).

More than half of the updated CGs included the rationale for updating $(61.7 \%$; $37 / 60)$, described changes in the scope and purpose between the updated CG and its predecessor $(56.7 \% ; 34 / 60)$, and reported the reviewed sections (66.7\%; 40/60) (Table 2, Fig. 2).

At the recommendation level, $26.7 \%(16 / 60)$ of the included CGs clearly labelled the recommendations as new, modified, or not changed, and 38.3\% (23/60) justified the changes. The justifications for changes commonly included a description of the new evidence that triggered the change in the recommendation and the changes between the new and old version of the recommendations (Table 2, Fig. 2).

The median score of the presentation domain on a 10point scale was 5.8 (range 1.7 to 10 ), and the agreement among the three reviewers was adequate (ICC 0.854; 95\% CI 0.701 to 0.941 ) (Table 3).

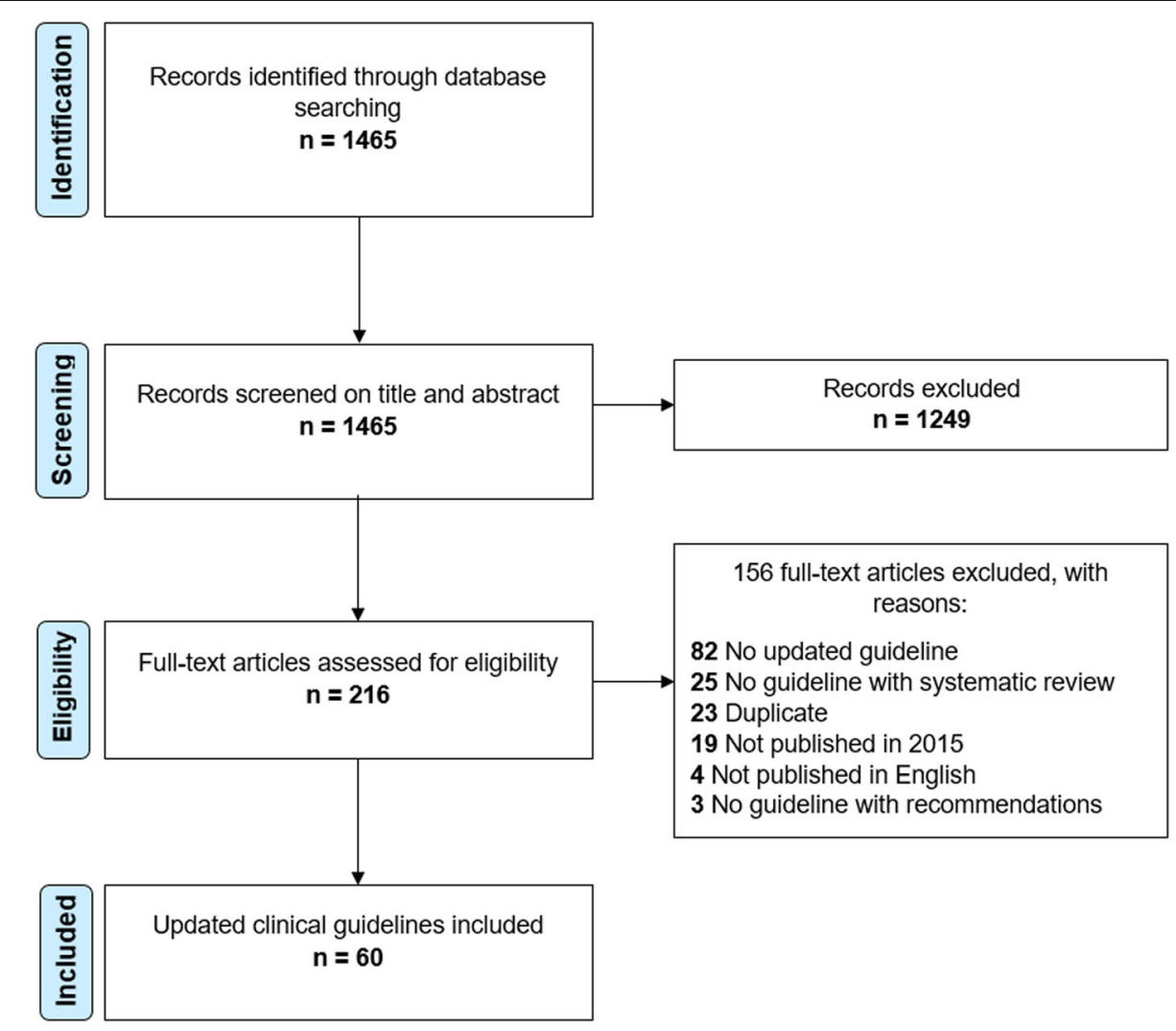

Fig. 1 Flow diagram of the screening process 
Table 1 Characteristics of the updated clinical guidelines

\begin{tabular}{ll}
\hline & $n(\%)$ \\
\hline Institution & \\
Country & \\
- North America & $37(61.7)$ \\
- Europe & $17(28.3)$ \\
- Asia & $4(6.7)$ \\
- International & $2(3.3)$ \\
Type of organisation & \\
- Scientific/professional society & $28(46.7)$ \\
- Public institution & $26(43.3)$ \\
- Other (Federal institute, NGO) & $6(10.0)$ \\
& \\
Updated clinical guidelines & \\
Scope & \\
- Management & $25(41.7)$ \\
- Treatment & $15(25.0)$ \\
- Screening & $9(15.0)$ \\
- Diagnosis & $7(11.7)$ \\
- Prevention & $4(6.7)$ \\
Health topic & \\
- Oncology & $16(26.7)$ \\
- Public health & $5(8.3)$ \\
- Menternal medicine & $3(5.0)$ \\
\hline
\end{tabular}

\section{Editorial independence}

Almost all included CGs described the panel participants in the updated version $(95.0 \% ; 57 / 60)$ and their respective conflicts of interest $(96.7 \% ; 58 / 60)$ (Table 2, Fig. 2). However, half of the updated CGs did not report the entity and/or the role of the funding body that financed the updated version $(50.0 \%$; 30/60).

The median score of the editorial independence domain on a 10 -point scale was 8.3 (range 3.3 to 10 ), and the agreement among the three reviewers was adequate (ICC 0.724; 95\% CI 0.534 to 0.860) (Table 3).

\section{Methodology of the updating process}

Most of the included CGs reported the methods used for searching and identifying new evidence (81.7\%; 49/60), selecting the evidence (78.3\%; 47/60), and assessing the quality of the included evidence $(76.7 \% ; 46 / 60)$ (Table 2 , Fig. 2). However, the methods for synthesising the evidence (46.7\%; 28/60), external review (38.3\%; 23/60), implementing the changes of the updated version in practice $(38.3 \%$; $23 / 60)$, or updating the new version $(40.0 \%$; 24/60) were reported less often in the included CGs.
The median score of the methodology domain on a 10-point scale was 5.7 (range 0 to 10), and the agreement among the three reviewers was adequate (ICC 0.886 ; $95 \%$ CI 0.771 to 0.952 ) (Table 3 ).

\section{Overall score}

The median overall score on a 10-point scale was 6.3 (range 3.1 to 10), and the agreement among the three reviewers was adequate (ICC $0.880 ; 95 \%$ CI 0.749 to 0.952 ) (Table 3).

CGs developed by a European or International institution obtained a higher overall score compared to North American or Asian institutions $(p=0.014)$ (Table 4). No significant differences in the overall score were found between CG differing in the type of organisation, scope, or topic.

\section{Discussion}

\section{Main findings}

Our study is the first systematic assessment of the reporting of the updating process in updated CGs using CheckUp. The presentation and methodology domains were reported less completely than the editorial independence domain. Particularly, the items regarding the presentation and justification of the updating process at recommendation level and the methods used for evidence synthesis, external review, implementing, and future updating were poorly reported. Both the domains and overall scores of the included CGs were highly variable. We identified only two (3.3\%) CGs with a perfect score (10-point overall score 10) [60, 74].

We observed an adequate ICC reliability between the three reviewers. The lowest ICC was found for the editorial independence domain, but the ICC domain score was still considered adequate. This was mainly due to some CGs that reported the panel participants and their conflicts of interest for those that were responsible for updating the CG; however, they failed to report the same information for those who were responsible for developing the preceding CG.

\section{Our results in the context of previous research Presentation of updated CGs}

Previous research showed that there was no clear improvement in the reporting or methodological quality after updating systematic reviews [85]. Similarly, Hasenfield et al. found that updated CGs were of worse methodological quality compared to their previous version [86]. Few studies have evaluated the optimal presentation formats of CGs in general $[87,88]$. Similarly, regarding the updating process of CGs, a wide variability in the formats used to present updated recommendations has been reported by our group [17]. In the field of systematic reviews, Newberry et al. [89] evaluated different formats for presenting 
Table 2 Item scores

\begin{tabular}{|c|c|}
\hline & Updated CGs reporting each item $n(\%)$ \\
\hline \multicolumn{2}{|l|}{ Presentation of the updated clinical guideline } \\
\hline Item 1: The updated version can be distinguished from the previous version of the clinical guideline. & $60(100)$ \\
\hline Item 2: The rationale for updating the clinical guideline is reported. & $37(61.7)$ \\
\hline $\begin{array}{l}\text { Item 3: Changes in the scope and purpose between the update and the previous version are described } \\
\text { and justified. }\end{array}$ & $34(56.7)$ \\
\hline Item 4: The sections reviewed in the updating process are described. & $40(66.7)$ \\
\hline $\begin{array}{l}\text { Item 5: Recommendations are clearly presented and labelled as new, modified, or not changed. } \\
\text { Deleted recommendations are clearly noted. }\end{array}$ & $16(26.7)$ \\
\hline Item 6: Changes in recommendations are reported and justified. & $23(38.3)$ \\
\hline \multicolumn{2}{|l|}{ Editorial independence } \\
\hline Item 7: The panel participants in the updated version are described. & $57(95.0)$ \\
\hline Item 8: Disclosures of interest of the group responsible for the updated version are recorded. & $58(96.7)$ \\
\hline Item 9: The role of the funding body for the updated version is identified and described. & $30(50.0)$ \\
\hline \multicolumn{2}{|l|}{ Methodology of the updating process } \\
\hline $\begin{array}{l}\text { Item 10: The methods used for searching and identifying new evidence in the updating process } \\
\text { are described. }\end{array}$ & $49(81.7)$ \\
\hline Item 11: The methods used for evidence selection in the updating process are described. & $47(78.3)$ \\
\hline $\begin{array}{l}\text { Item 12: The methods used to assess the quality of the included evidence in the updating process } \\
\text { are described. }\end{array}$ & $46(76.7)$ \\
\hline Item 13: The methods used for evidence synthesis in the updating process are described. & $28(46.7)$ \\
\hline Item 14: The methods used for external review of the updated version are described. & $23(38.3)$ \\
\hline $\begin{array}{l}\text { Item 15: The methods and plan for implementing the changes of the updated version in practice } \\
\text { are described. }\end{array}$ & $23(38.3)$ \\
\hline Item 16: The plan and methods for updating the new version in the future are reported. & $24(40.0)$ \\
\hline
\end{tabular}

the results of updated systematic reviews. One of their conclusions was that different interest groups have different information needs. For example, health managers preferred to have access to all data and the analysis of a systematic review (the original and the updated), whereas clinicians prefer a synthesis that clearly shows what has been changed [89].

In our study, we have identified that, in particular, the presentation of updated recommendations is not optimal, with recommendations often not presented or not clearly labelled as new, modified, or not changed. This might confuse readers who might not be able to identify which recommendations are updated and which ones remain identical. Additionally, the modifications conducted in recommendations are often not described nor justified.

\section{Reporting the editorial independence}

The same principle regarding editorial independence for developing new CGs should be applied to the updating process [90]. Previous studies, in which the quality of CGs was reviewed with the Appraisal of Guidelines for Research and Evaluation II (AGREE II) instrument, have observed low scores in the domain of editorial independence
$[91,92]$. We found similar results for the source of funding. However, most of the included updated CGs in our study reported the panel members and their conflicts of interest.

\section{Reporting the methodology of the updating process}

Until now, most of the methodological research regarding the updating process of CGs concerned the identification and assessment of new evidence (described commonly as the surveillance process) [18]. However, the complete updating process, including the presentation and justification of the updating process at recommendation level, has received less attention. CG developers possibly assume that the complete updating process is equal to the development process of the initial CG [19]. This could explain why the items that have a certain overlap with the development process (i.e. search strategy, evidence selection, and quality assessment) have higher scores compared to the updating items that are methodologically different from the development process (i.e. synthesis, external review, implementation of changes, and updating in the future) of the initial CG. Although the methods for developing CGs evolve rapidly [93], the updating process still does not follow this progress correspondingly [18, 19, 94, 95]. 


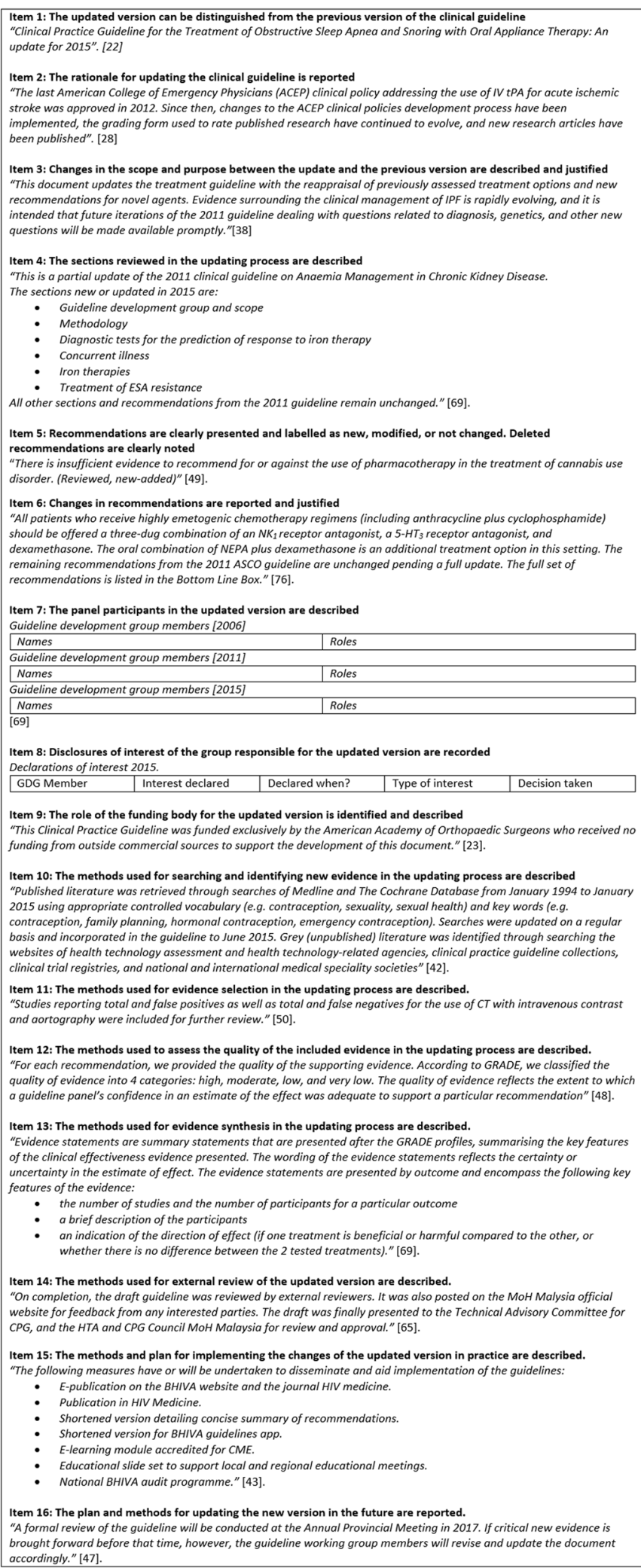

Fig. 2 Reporting examples of the included updated CGs 
Table 3 Domains, overall, and agreement scores

\begin{tabular}{lll}
\hline & $\begin{array}{l}\text { Score } \\
\text { median (range) }\end{array}$ & $\begin{array}{c}\text { Agreement } \\
\text { ICC (95\% Cl) }\end{array}$ \\
\hline Domain & & \\
- Presentation of the updated CG & $5.8(1.7-10)$ & $0.854(0.701-0.941)$ \\
- Editorial independence & $8.3(3.3-10)$ & $0.724(0.534-0.860)$ \\
- Methodology of the updating process & $5.7(0-10)$ & $0.886(0.771-0.952)$ \\
Overall & $6.3(3.1-10)$ & $0.880(0.749-0.952)$ \\
\hline
\end{tabular}

a 10 -point scale (10 as the best possible score)

ICC intraclass coefficient, $\mathrm{Cl}$ confidence interval

When updating CGs, developers need to pay special attention to the implementation implications of the changes introduced in updated CGs [96]. This can be done by exploring facilitators and barriers, by developing supporting materials, or by providing audit criteria [97]. Recently, GRADE has published Evidence to Decision frameworks to support developers to systematically consider this aspect and other criteria [98]. As living CGs become more common practice [99], developers will need to assess to what extent more frequent changes in

Table 4 Overall scores stratified by characteristics of the updated clinical guidelines

\begin{tabular}{|c|c|c|}
\hline & $\begin{array}{l}\text { Overall score } \\
\text { median (range) }\end{array}$ & $p$ value \\
\hline \multicolumn{3}{|l|}{ Institution } \\
\hline \multicolumn{3}{|l|}{ Country } \\
\hline - Europe & $8.1(4.4-10.0)$ & \multirow{4}{*}{0.014} \\
\hline - International & $7.8(6.9-8.8)$ & \\
\hline - Asia & $5.6(3.8-6.3)$ & \\
\hline - North America & $5.6(3.1-8.1)$ & \\
\hline \multicolumn{3}{|l|}{ Type of organisation } \\
\hline - Public institution & $6.3(3.1-10.0)$ & \multirow{3}{*}{0.617} \\
\hline - Scientific/professional society & $6.3(3.1-8.8)$ & \\
\hline - Other (Federal institute, NGO) & $4.4(3.8-8.1)$ & \\
\hline \multicolumn{3}{|l|}{ Updated clinical guidelines } \\
\hline \multicolumn{3}{|l|}{ Scope } \\
\hline - Diagnosis & $8.1(5.0-9.4)$ & \multirow{5}{*}{0.097} \\
\hline - Prevention & $5.6(4.4-6.3)$ & \\
\hline - Management & $6.3(3.1-10.0)$ & \\
\hline - Treatment & $6.3(4.4-8.8)$ & \\
\hline - Screening & $3.8(3.1-8.1)$ & \\
\hline \multicolumn{3}{|l|}{ Health topic } \\
\hline - Mental health & $6.9(5.0-8.1)$ & \multirow{5}{*}{0.099} \\
\hline - Oncology & $6.3(3.8-9.4)$ & \\
\hline - Internal medicine & $6.3(5.6-8.1)$ & \\
\hline - Public health & $3.8(3.1-3.8)$ & \\
\hline - Others & $6.3(3.1-10.0)$ & \\
\hline
\end{tabular}

a 10 -point scale (10 as the best possible score) recommendations impact their implementability and optimisation of patient care.

\section{Strengths and limitations}

Our study has several strengths. We followed a rigorous and transparent approach and developed a protocol that is available from the authors on request. Additionally, three reviewers independently conducted the assessment of the included CGs and adequate agreement was found.

Our study has some limitations. It is possible that we did not identify all updated CGs that would meet our inclusion criteria due to suboptimal indexing of CGs in biomedical databases, which may limit the representativeness of the results. Additionally, one eligibility criterion was also an item from the checklist, which might have led to the inclusion of more high-quality updated CGs. Consequently, our results might be an overestimate, and the actual reporting be actually worse than our findings.

\section{Implications for practice and research}

When CG developers are interested in updating CGs, we suggest firstly assessing the quality of CGs using the AGREE II instrument. After that, we suggest to (1) prioritise the update of high-quality CGs or (2) improve the methodological quality of the CG during the updating process. After the updating process, CG developers can assess the reporting of the updating process using CheckUp. Consequently, when both the AGREE II and CheckUp instruments are properly applied, developers will have a complete and detailed overview of the quality of the developing and updating processes. Afterwards, if applicable, the prioritisation process of updating CGs can be conducted [11].

There is currently no gold standard for updating CGs $[18,19,94,95]$. Although CheckUp does not evaluate the quality of the updating process, CG developers can use it to inform their updating processes. Additionally, CheckUp can be used by interested CG users to assess whether updated CGs are in alignment with the CheckUp items, and editors of scientific journals that publish updated CGs may request the completion of CheckUp from the CG authors [20]. 
It would be relevant to monitor the use and the impact of CheckUp in the updating CG field over the next few years, potentially using this study as a baseline evaluation before the publication of CheckUp. Finally, we invite users to comment on the items and the usability of CheckUp contacting the corresponding author of this publication.

We suggest users of CheckUp to assess the reporting of the updating process in updated CGs by at least three calibrate reviewers. We involved three reviewers for convenience to avoid ties. Further examinations of CheckUp are required to determine if the inter-observer agreement between two reviewers would be adequate. Clinical expertise regarding the clinical area of the CG is not required; however, methodological comprehension on the updating process of CGs is highly desirable. To facilitate understanding of the domain scores and overall scores, we have transformed the domain and overall scores to a 10-point scale score.

\section{Conclusions}

The reporting of the updating process in updated CGs is suboptimal. Presentation of updated CGs and the methodology of the updating process where areas where more work is needed. We advise CG developers to use CheckUp to improve the reporting of updated CGs. CheckUp can also be used to assess the updating process in updated CGs and as a blueprint that could be used to inform specific updating methods and reporting strategies.

\section{Additional files}

Additional file 1: Literature search strategy. (DOCX 27 kb)

Additional file 2: Excluded full text references including reason for exclusion. (DOCX $52 \mathrm{~kb}$ )

\section{Abbreviations \\ AGREE: Appraisal of Guidelines for Research and Evaluation; CG: Clinical guideline; CheckUp: Checklist for the Reporting of Updated Guidelines; Cl: Confidence interval; G-I-N: Guidelines International Network; ICC: Interclass Correlations Coefficient}

\section{Acknowledgements}

Robin W. M. Vernooij is a doctoral candidate at the Paediatrics, Obstetrics and Gynaecology and Preventive Medicine Department, Universitat Autònoma de Barcelona, Barcelona, Spain.

\section{Availability of data and materials}

The datasets used and/or analysed during the current study are available from the corresponding author on reasonable request.

\section{Authors' contributions}

$R V$, LM, MB, and PA-C contributed to conceiving the study. All authors designed the study. RV conducted the searches. RV, IDF, LHA, and MHFP contributed to screening and extracting the data. RV, LM, and PA-C contributed to writing the manuscript. All authors contributed to commenting and editing of review drafts. All authors read and approved the final manuscript.

\section{Funding}

This project is funded by research grants from the Instituto de Salud Carlos III through the project 'PI14/02006' (co-funded by European Regional Development
Fund/European Social Fund 'Investing in your future'). LMG is funded by a Juan Rodés contract from the Instituto de Salud Carlos III (JR15/00004). PAC is supported by a Miguel Servet investigator contract from the Instituto de Salud Carlos III (CPII15/0034). The funders had no role in the study design, data collection and analysis, interpretation of data, and writing the manuscript.

Ethics approval and consent to participate

Not applicable

\section{Consent for publication}

Not applicable

\section{Competing interests}

The authors declare that they have no competing interests.

\section{Publisher's Note}

Springer Nature remains neutral with regard to jurisdictional claims in published maps and institutional affiliations.

\section{Author details}

${ }^{1}$ Iberoamerican Cochrane Centre, Biomedical Research Institute Sant Pau (IIB Sant Pau), Barcelona, Spain. ${ }^{2}$ Department of Health Research Methods, Evidence and Impact; McMaster University, Hamilton, Canada. ${ }^{3}$ Department of Pediatrics, University of Antioquia, Medellin, Colombia. ${ }^{4}$ University Medical Center Utrecht, Utrecht, The Netherlands. ${ }^{5}$ Department of Oncology, McMaster University, Hamilton, Canada. ${ }^{6} \mathrm{CIBER}$ of Epidemiology and Public Health (CIBERESP), Madrid, Spain.

Received: 2 June 2017 Accepted: 3 October 2017

Published online: 12 October 2017

\section{References}

1. Laine C, Taichman DB, Mulrow C. Trustworthy clinical guidelines. Ann Intern Med. 2011;154(11):774-5

2. loannidis JP. The mass production of redundant, misleading, and conflicted systematic reviews and meta-analyses. Milbank Q. 2016;94(3):485-514.

3. Bastian H, Glasziou P, Chalmers I. Seventy-five trials and eleven systematic reviews a day: how will we ever keep up? PLoS Med. 2010;7:e1000326.

4. Martínez García L, Sanabria AJ, García Alvarez E, Trujillo-Martín MM, Etxeandia-Ikobaltzeta I, Kotzeva A, et al. The validity of recommendations from clinical guidelines: a survival analysis. CMAJ. 2014;186(16):1211-9.

5. Alderson LJ, Alderson P, Tan T. Median life span of a cohort of National Institute for Health and Care Excellence clinical guidelines was about 60 months. J Clin Epidemiol. 2014;67(1):52-5.

6. Neuman MD, Goldstein JN, Cirullo MA, Schwartz JS. Durability of class I American College of Cardiology/American Heart Association clinical practice guideline recommendations. JAMA. 2014;311(20):2092-100.

7. Lyratzopoulos G, Barnes S, Stegenga H, Peden S, Campbell B. Updating clinical practice recommendations: is it worthwhile and when? Int J Technol Assess Health Care. 2012;28(1):29-35.

8. Shekelle PG, Ortiz E, Rhodes S, Morton SC, Eccles MP, Grimshaw JM, et al. Validity of the Agency for Healthcare Research and Quality clinical practice guidelines: how quickly do guidelines become outdated? JAMA. 2001; 286(12):1461-7.

9. Martínez García L, Pardo-Hernandez H, McFarlane E, Sanabria AJ, Sparrow K, Alonso-Coello P, the G-I-N updating guidelines working group OBO. UpGlossary: Guidance on terminology and definitions for updating clinical guidelines. Cape Town: Global Evidence Summit 2017.

10. Agbassi $\mathrm{C}$, Messersmith $\mathrm{H}, \mathrm{McNair} \mathrm{S}$, Brouwers M. Priority-based initiative for updating existing evidence-based clinical practice guidelines: the results of two iterations. J Clin Epidemiol. 2014;67(12):1335-42.

11. Martínez García L, Pardo H, Superchi C, Niño de Guzman E, Ballesteros M, Ibargoyen Roteta $N$, et al. Updating health decision-making tools: a systematic review of prioritisation processes. J Clin Epidemiol. 2017;86: $11-24$.

12. Martinez Garcia L, Sanabria AJ, Araya I, Lawson J, Solà I, Vernooij RW, et al. Efficiency of pragmatic search strategies to update clinical guidelines recommendations. BMC Med Res Methodol. 2015:15:57.

13. Gartlehner G, West SL, Lohr KN, Kahwati L, Johnson JG, Harris RP, et al. Assessing the need to update prevention quidelines: a comparison of two methods. Int J Qual Health Care. 2004;16(5):399-406. 
14. Johnston ME, Brouwers MC, Browman GP. Keeping cancer guidelines current: results of a comprehensive prospective literature monitoring strategy for twenty clinical practice guidelines. Int J Technol Assess Health Care. 2003;19(4):646-55.

15. Eccles M, Rousseau N, Freemantle N. Updating evidence-based clinical guidelines. J Health Serv Res Policy. 2002;7(2):98-103.

16. Parmelli E, Papini D, Moja L, Bandieri E, Belfiglio M, Ciccone G, et al. Updating clinical recommendations for breast, colorectal and lung cancer treatments: an opportunity to improve methodology and clinical relevance. Ann Oncol. 2011;22(1):188-94.

17. Martinez Garcia L, McFarlane E, Barnes S, Sanabria AJ, Alonso-Coello P, Alderson P. Updated recommendations: an assessment of NICE clinical guidelines. Implement Sci. 2014;9:72.

18. Martinez Garcia L, Arevalo-Rodriguez I, Sola I, Haynes RB, Vandvik PO, Alonso-Coello P, et al. Strategies for monitoring and updating clinical practice guidelines: a systematic review. Implement Sci. 7:109.

19. Vernooij RW, Sanabria AJ, Sola I, Alonso-Coello P, Martínez GL. Guidance for updating clinical practice guidelines: a systematic review of methodological handbooks. Implement Sci. 2014:9:3.

20. Vernooij RW, Alonso-Coello P, Brouwers M, CheckUp Panel. Reporting items for updated clinical guidelines: checklist for the reporting of updated guidelines (CheckUp). PLoS medicine. 2017;14: e1002207.

21. Grupo de trabajo para la actualización del Manual de Elaboración de GPC. Elaboración de Guías de Práctica Clínica en el Sistema Nacional de Salud. Actualización del Manual Metodológico. Madrid: Ministerio de Sanidad, Servicios Sociales e lgualdad - GuíaSalud; 2016.

22. Eady EA, Layton AM, Sprakel J, BWM A, Fedorowicz Z, van Zuuren EJ. AGREE II assessments of recent acne treatment guidelines: how well do they reveal trustworthiness as defined by the Institute of Medicine (IOM) criteria? Br J Dermatol. 2017. doi:10.1111/bjd.15777.

23. Moher D, Liberati A, Tetzlaff J, Altman DG, The PRISMA Group. Preferred reporting items for systematic reviews and meta-analyses: the PRISMA statement. BMJ. 2009;339:b2535.

24. Landis JR, Koch GG. The measurement of observer agreement for categorical data. Biometrics. 1977;33:159-74.

25. American Academy of Dental Sleep Medicine/American Academy of Sleep Medicine. Clinical practice guideline for the treatment of obstructive sleep apnea and snoring with oral appliance therapy: an update for 2015:2015.

26. American Academy of Orthopaedic Surgeons. American Academy of Orthopaedic Surgeons clinical practice guideline on the treatment of pediatric diaphyseal femur fracture; 2015.

27. American Academy of Otolaryngology-Head and Neck Surgery. Clinical practice guideline (update): adult sinusitis; 2015.

28. American Academy of Sleep Medicine. Clinical practice guideline for the treatment of intrinsic circadian rhythm sleep-wake disorders: advanced sleep-wake phase disorder (ASWPD), delayed sleep-wake phase disorder (DSWPD), non-24-hour sleep-wake rhythm disorder (N24SWD), and irregular sleep-wake rhythm disorder (ISWRD). An update for 2015; 2015.

29. American Cancer Society. Breast cancer screening for women at average risk: 2015 guideline update from the American Cancer Society; 2015.

30. American College of Chest Physicians. Somatic cough syndrome (previously referred to as psychogenic cough) and tic cough (previously referred to as habit cough) in adults and children: CHEST guideline and Expert Panel report; 2015.

31. American College of Emergency Physicians. Clinical policy: use of intravenous tissue plasminogen activator for the management of acute ischemic stroke in the emergency department; 2015.

32. American Dental Association. The use of prophylactic antibiotics prior to dental procedures in patients with prosthetic joints: evidence-based clinical practice guideline for dental practitioners - a report of the American Dental Association Council on Scientific Affairs; 2015.

33. American Geriatrics Society. American Geriatrics Society 2015 updated Beers Criteria for potentially inappropriate medication use in older adults; 2015.

34. Stav W. Occupational therapy Occupational therapy practice guidelines for driving and community mobility for older adults. Bethesda (MD)Ñ American Occupational Therapy Association (AOTA); 2015.

35. American Psychiatric Association. Practice guidelines for the psychiatric evaluation of adults, third edition; 2015.

36. American Society of Anesthesiologists. Practice guidelines for perioperative blood management: an updated report by the American Society of Anesthesiologists Task Force on Perioperative Blood Management; 2015.
37. American Society of Anesthesiologists. Practice advisory on anesthetic care for magnetic resonance imaging: an updated report by the American Society of Anesthesiologists Task Force on Anesthetic Care for Magnetic Resonance Imaging; 2015

38. American Society of Clinical Oncology. Recommendations for the use of WBC growth factors: American Society of Clinical Oncology clinical practice guideline update; 2015.

39. American Society of Clinical Oncology. Systemic therapy for stage IV nonsmall-cell lung cancer: American Society of Clinical Oncology clinical practice guideline update; 2015.

40. American Society of Clinical Oncology. Use of biomarkers to guide decisions on systemic therapy for women with metastatic breast cancer: American Society of Clinical Oncology clinical practice guideline; 2015.

41. Raghu G, Rochwerg B, Zhang Y, Garcia CA, AzumaA BJ, et al. An official ATS/ ERS/JRS/ALAT clinical practice guideline: treatment of idiopathic pulmonary fibrosis. An update of the 2011 clinical practice guideline. Am J Respir Crit Care Med. 2015;192(2):e3-19.

42. American Urological Association. Castration-resistant prostate cancer: AUA guideline; 2015

43. Atkins DL, Berger S, Duff JP, Gonzales JC, Hunt EA, Joyner BL, et al. Part 11: pediatric basic life support and cardiopulmonary resuscitation quality: 2015 American Heart Association guidelines update for cardiopulmonary resuscitation and emergency cardiovascular care (reprint). Circulation. 2015; 132(18 Suppl 2):S519-25.

44. Black A, Guilbert E, Co Authors, Costescu D, Dunn S, Fisher W, et al. Canadian contraception consensus (part 2 of 4). J Obstet Gyneacol Can 2015;37(11):1033-1039.

45. Black A, Guilbert E, Co Authors, Costescu D, Dunn S, Fisher W, et al. Canadian contraception consensus (part 1 of 4). J Obstet Gyneacol Can. 2015:37(10):936-942.

46. British HIV Association. British HIV Association guidelines for the treatment of HIV-1-positive adults with antiretroviral therapy 2015; 2015.

47. Canadian Task Force on Preventive Health Care. Recommendations for prevention of weight gain and use of behavioural and pharmacological interventions to manage overweight and obesity in adults in primary care; 2015.

48. CancerControl Alberta. Systemic therapy for well and moderately differentiated unresectable pancreatic neuroendocrine tumours; 2015

49. CancerControl Alberta. Systemic therapy for unresectable stage III or metastatic cutaneous melanoma; 2015.

50. CancerControl Alberta. Merkel cell carcinoma; 2015.

51. Belgian Health Care Knowledge Centre. What are the recommended clinical assessment and screening tests during pregnancy?; 2015

52. Department of Defense/Department of Veterans Affairs. VA/DoD clinical practice guideline for the management of substance use disorders; 2015.

53. Eastern Association for the Surgery of Trauma. Evaluation and management of blunt traumatic aortic injury: a practice management quideline from the Eastern Association for the Surgery of Trauma; 2015.

54. National Institute for Health and Care Excellence. Tuberculosis (CG117); 2015.

55. National Institute for Health and Care Excellence. Diabetes in pregnancy (CG63); 2015.

56. National Institute for Health and Care Excellence. Diabetes in children and young people (CG); 2015.

57. National Institute for Health and Care Excellence. Type 1 diabetes (CG15); 2015

58. National Institute for Health and Care Excellence. Referral for suspected cancer (CG27); 2015.

59. National Institute for Health and Care Excellence. Coeliac disease (CG86); 2015.

60. National Institute for Health and Care Excellence. Type 2 diabetes: the management of type 2 diabetes (update) (CG66); 2015.

61. National Institute for Health and Care Excellence. Type 2 diabetes-footcare (CG10); 2015.

62. National Institute for Health and Care Excellence. Violence (CG25); 2015.

63. Siu AL, U.S. Preventive Services Task Force. Screening for iron deficiency anemia and iron supplementation in pregnant women to improve maternal health and birth outcomes: U.S. Preventive Services Task Force recommendation statement. Ann Intern Med. 2015;163(7):529-36.

64. Siu AL, U.S. Preventive Services Task Force. Screening for iron deficiency anemia in young children: USPSTF recommendation statement. Pediatrics. 2015;136(4):746-52. 
65. Siu AL, U.S. Preventive Services Task Force. Screening for abnormal blood glucose and type 2 diabetes mellitus: U.S. Preventive Services Task Force recommendation statement. Ann Intern Med. 2015;163(11):861-8.

66. Siu AL, U.S. Preventive Services Task Force. Screening for high blood pressure in adults: U.S. Preventive Services Task Force recommendation statement. Ann Intern Med. 2015;163(10):778-86.

67. Siu AL, U.S. Preventive Services Task Force. Behavioral and pharmacotherapy interventions for tobacco smoking cessation in adults, including pregnant women: U.S. Preventive Services Task Force recommendation statement. Ann Intern Med. 2015;163(8):622-34.

68. Malaysia Health Technology Assessment Section (MaHTAS). Management of cervical cancer (second edition); 2015.

69. Malaysia Health Technology Assessment Section (MaHTAS). Management of type 2 diabetes mellitus (5th edition); 2015.

70. Malaysia Health Technology Assessment Section (MaHTAS). Management of dengue infection in adults (third edition); 2015.

71. Miyazaki M, Yoshitomi H, Miyakawa S, Uesaka K, Unno M, Endo I, et al. Clinical practice guidelines for the management of biliary tract cancers 2015: the 2nd English edition. J Hepatobiliary Pancreat Sci. 2015;22(4): 249-73.

72. National Clinical Guideline Centre. Anaemia management in people with chronic kidney disease; 2015.

73. National Collaborating Centre for Nursing and Supportive Care. Irritable bowel syndrome in adults: diagnosis and management of irritable bowel syndrome in primary care; 2015.

74. National Collaborating Centre for Women. Diabetes (type 1 and type 2) in children and young people: diagnosis and management; 2015.

75. National Institute for Health and Care Excellence. Prophylaxis against infective endocarditis: antimicrobial prophylaxis against infective endocarditis in adults and children undergoing interventional procedures; 2015.

76. National Kidney Foundation. KDOQI clinical practice guideline for hemodialysis adequacy: 2015 update; 2015.

77. Scottisch Intercollegiate Guidelines Network (SIGN). Diagnosis and management of epilepsy in adults (SIGN CPG 143); 2015.

78. Lyman GH, Bohlke K, Khorana AA, Kuderer NM, Lee AY, Arcelus Jl, et al. Venous thromboembolism prophylaxis and treatment in patients with cancer: American Society of Clinical Oncology practice guideline update 2014. J Clin Oncol. 2015;33(6):654-6.

79. Hesketh PJ, Bohlke K, Lyman GH, Basch E, Chesney M, Clark-Snow RA, et al. Antiemetics: American Society of Clinical Oncology focused guideline update. J Clin Oncol. 2016;34(4):381-6.

80. Hwang JP, Somerfield MR, De A-J, Cryer DR, Feld JJ, Kramer BS, et al. Hepatitis B virus screening for patients with cancer before therapy: American Society of Clinical Oncology provisional clinical opinion update. J Clin Oncol. 2015;33(19):2212-20.

81. Allegra CJ, Rumble RB, Hamilton SR, Mangu PB, Roach N, Hantel A, et al. Extended RAS gene mutation testing in metastatic colorectal carcinoma to predict response to anti-epidermal growth factor receptor monoclonal antibody therapy: American Society of Clinical Oncology provisional clinical opinion update 2015. J Clin Oncol. 2016;34(2):179-85.

82. Park IU, Introcaso C, Dunne EF. Human papillomavirus and genital warts: a review of the evidence for the 2015 Centers for Disease Control and Prevention sexually transmitted diseases treatment guidelines. Clin Infect Dis. 2015;61(Suppl 8):S849-55.

83. Prica A, Baldassarre F, Hicks LK, Imrie K, Kouroukis TC, Cheung M, et al. Rituximab in lymphoma and chronic lymphocytic leukemia: a clinical practice guideline, version 3; 2015.

84. Registered Nurses' Association of Ontario. Person- and family-centred care; 2015.

85. Shea B, Boers M, Grimshaw JM, Hamel C, Bouter LM. Does updating improve the methodological and reporting quality of systematic reviews? BMC Med Res Methodol. 2006;6:27.

86. Hasenfeld R, Shekelle PG. Is the methodological quality of guidelines declining in the US? Comparison of the quality of US Agency for Health Care Policy and Research (AHCPR) guidelines with those published subsequently. Qual Saf Health Care. 2003;12(6):428-34.

87. Brandt L, Vandvik PO, Alonso-Coello P, Akl EA, Thornton J, Rigua D, et al. Multilayered and digitally structured presentation formats of trustworthy recommendations: a combined survey and randomised trial. BMJ Open. 2017;7(2):e011569.
88. Kastner M, Bhattacharyya O, Hayden L, Makarski J, Estey E, Durocher L, et al. Guideline uptake is influenced by six implementability domains for creating and communicating guidelines: a realist review, 498. J Clin Epidemiol. 68(5):-509.

89. Newberry SJ, Shekelle PG, Vaiana M, Motala A. Reporting the findings of updated systematic reviews of comparative effectiveness: how do users want to view new information? Rockville: Agency for Healthcare Research and Quality; 2013

90. Schunemann HJ, Al-Ansary LA, Forland F, Kersten S, Komulainen J, Kopp IB, et al. Guidelines international network: principles for disclosure of interests and management of conflicts in guidelines. Ann Intern Med. 2015;163(7): 548-53.

91. Armstrong JJ, Goldfarb AM, Instrum RS, MacDermid JC. Improvement evident but still necessary in clinical practice guideline quality: a systematic review. J Clin Epidemiol. 2017:81:13-21.

92. Alonso-Coello P, Irfan A, Sola I, Gich I, Delgado-Noguera M, Rigau D, et al. The quality of clinical practice guidelines over the last two decades: a systematic review of guideline appraisal studies. Qual Saf Health Care. 2010; 19(6):e58.

93. Murad MH. Clinical practice guidelines: a primer on development and dissemination. Mayo Clin Proc. 2017;92(3):423-33.

94. Alonso-Coello P, Martinez Garcia L, Carrasco JM, Solà I, Qureshi S, Burgers JS, et al. The updating of clinical practice guidelines: insights from an international survey. Implement Sci. 2011;6:107.

95. Becker M, Neugebauer EA, Eikermann M. Partial updating of clinical practice guidelines often makes more sense than full updating: a systematic review on methods and the development of an updating procedure. J Clin Epidemiol. 2014;67(1):33-45.

96. National Institute for Health and Care Excellence. Developing NICE guidelines: the manual [internet]. London: National Institute for Health and Care Excellence (NICE; 2015.

97. Chan W, Pearson TA, Bennett GC, Cushman WC, Gaziano TA, Gorman PN, et al. ACC/AHA special report: clinical practice guideline implementation strategies: a summary of systematic reviews by the NHLBI implementation science work group: a report of the American College of Cardiology/ American Heart Association Task Force on clinical practice guidelines. J Am Coll Cardiol. 2017;69(8):1076-92.

98. Alonso-Coello P, Oxman AD, Moberg J, Brignardello-Petersen R, Akl EA, Davoli $M$, et al. GRADE evidence to decision (EtD) frameworks: a systematic and transparent approach to making well informed healthcare choices. 2: clinical practice guidelines. BMJ. 2016;i2089:353.

99. Martínez García L, Pardo-Hernandez H, Sanabria A, Alonso-Coello P, Pregnancy Clinical Guideline Updating Working Group. Continuous surveillance of a pregnancy clinical guideline: an early experience. Systematic Reviews. 2017;6:143.

\section{Submit your next manuscript to BioMed Central and we will help you at every step:}

- We accept pre-submission inquiries

- Our selector tool helps you to find the most relevant journal

- We provide round the clock customer support

- Convenient online submission

- Thorough peer review

- Inclusion in PubMed and all major indexing services

- Maximum visibility for your research

Submit your manuscript at www.biomedcentral.com/submit
Biomed Central 